\title{
Study on Strategies of Optimizing Service Contact for New Rural Waste Classification System
}

\author{
Sun Ningna ${ }^{1, \text { a }}$, Peng yue ${ }^{* 1, b}$ \\ ${ }^{1}$ Jiangsu University Zhenjiang, 212000, China
}

\begin{abstract}
This paper studied the rural waste classification system to find out practical strategies to optimize service encounter involved in rural waste classification system. It identified and analyzed the encounter points affecting each link of service and user experience. The paper proposed to construct service procedures to simplify waste classification service in an effort to provide guided services accessible to villagers, optimize collaborative services aiming at accurate delivery, offer incentives to village households for accurate waste classification and give instructions on the blueprint of services.
\end{abstract}

\section{Introduction}

In recent years, waste classification in new rural areas has started to emerge. Although relevant laws and regulations have been formulated and the bins for classification and garbage collection have been put in place, the lack of environmental awareness among rural residents and the absence of a system for waste classification, collection, transportation and treatment have prevented the effective implementation of waste classification and the utilization of waste bins ${ }^{[1]}$. Problems like this not only reduced enthusiasm of villagers to participate in garbage classification, but also lowered the efficiency of staff offering recycling services, which greatly affects the overall user satisfaction of the rural waste classification system. In this study, the service encounter theory was applied to the new rural waste classification system, which can effectively optimize the waste classification and recycling system, improve user satisfaction, and help build beautiful villages.

\section{Service Design and Service Encounter Theory}

\subsection{Service design and service encounter theory}

Service design is traditionally defined as the process in which elements related to service encounter must be identified, arranged and designed once it has a role in user experience in an effort to deliver value-added services and improve the quality of services ${ }^{[2]}$. Service encounter theory mainly studies the dynamic interaction of service recipients in service scenarios, including emotional interactions between service participants and contacts between service participants and visual information, service facilities and other subjects ${ }^{[3]}$. The encounter point of service is the core of the service encounter theory in the field of service design, and the "vital dot" connecting stakeholders, product facilities, information interface and other elements on the service path, which can directly affect the service perception and evaluation of service recipients at any time.

\subsection{Classification of service encounter points}

Service encounter points can be classified into physical encounter points, information encounter points and interpersonal encounter points in the design of public services. Physical encounter point is the most common and tangible encounter point. Information encounter point refers to the tangible interface carrying information. Interpersonal encounter point refers to the interactive contact between people, focusing on the emotional perception among service participants ${ }^{[4]}$.

\subsection{Optimizing routes of service encounter of waste classification system}

The optimization of service encounter includes three steps: identification, division and optimization (Figure 1).

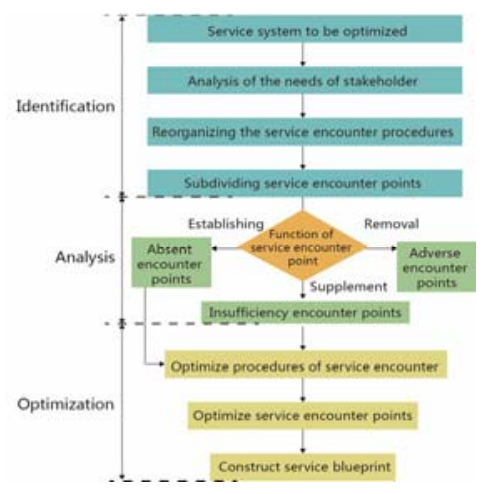

Figure 1: Optimizing the Route of Service Encounter 
(1) Identification: Observe the feelings and feedback of users in each service link and find out the needs of stakeholders, sort out the procedures of service encounter based on sequence of the time axis, divide the key encounter points that affect the experience of users ${ }^{[5]}$, present them in the form of physics, information and interpersonal relationship, and build the layered model of "service encounter link-service encounter process-service encounter point"(Figure 2);

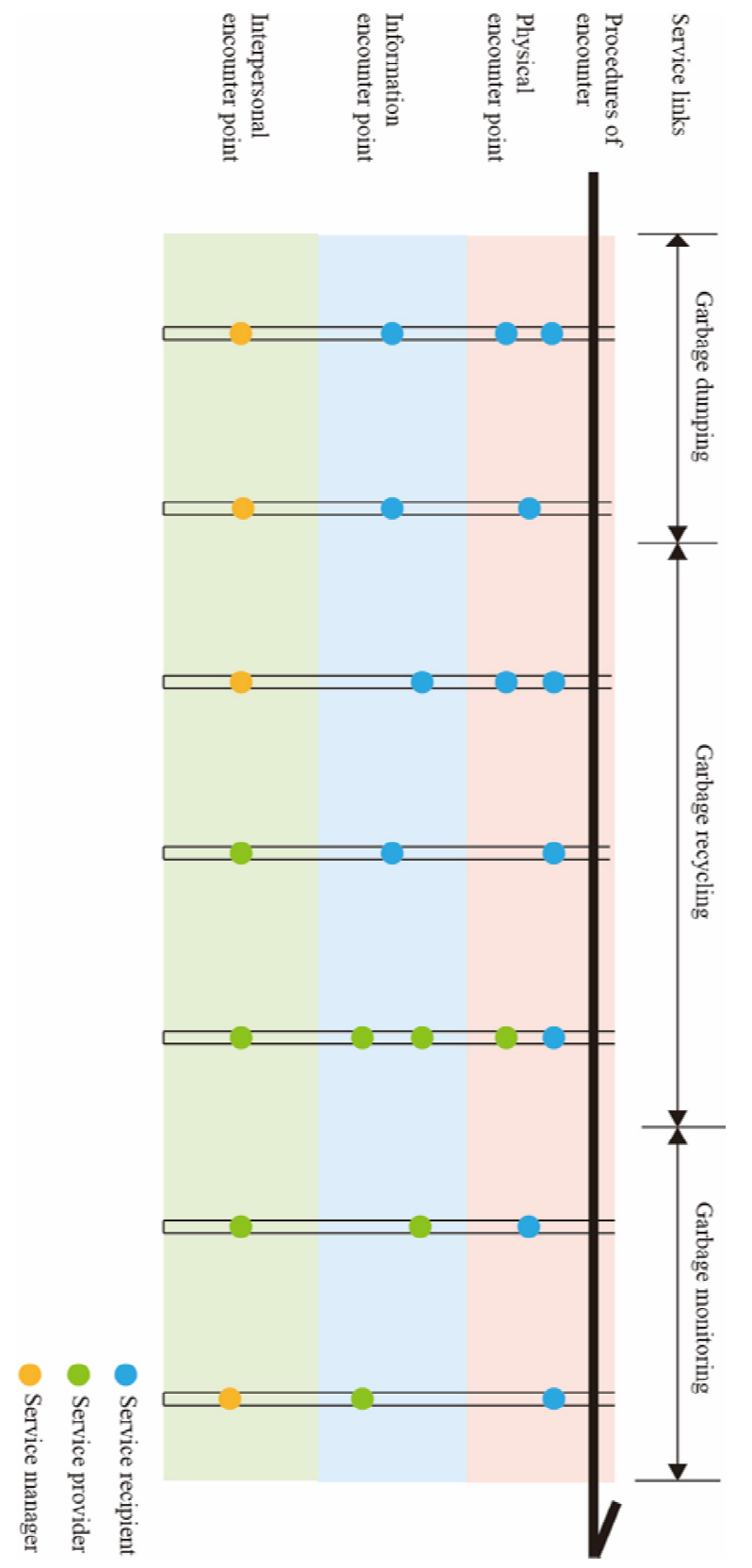

Figure 2: Layered Model of Service Encounter

(2) Analysis: List and analyze the service encounter points in the procedures of waste classification system ${ }^{[6]}$, find out the causes of negative encounter points, remove harmful encounter points that generate negative emotions among users, correct or supplement encounter points that affect experience, create effective encounter points that are absent in the system, and ensure effective improvement of each contact point.

(3) Optimization: The improvement of the service encounter relies on optimizing the service encounter procedures and service encounter points, including user journey, front-end and back-end service process and support in the service system ${ }^{[7]}$. Visualize the services by using the service blueprint to ensure an appropriate structure of the service system.

\section{Identification and Analysis of Service Encounter in New Rural Waste Classification System}

\subsection{Analysis of Stakeholders' Needs in New Rural Waste Classification System}

Individuals and groups that influence the classification and recycling of garbage in rural areas or participate in the classification of garbage in rural areas can be defined as stakeholders in the rural waste classification system ${ }^{[8]}$, which mainly includes villagers, sanitation staff, members of the village committee. Presented as a stakeholder map (Figure 3).

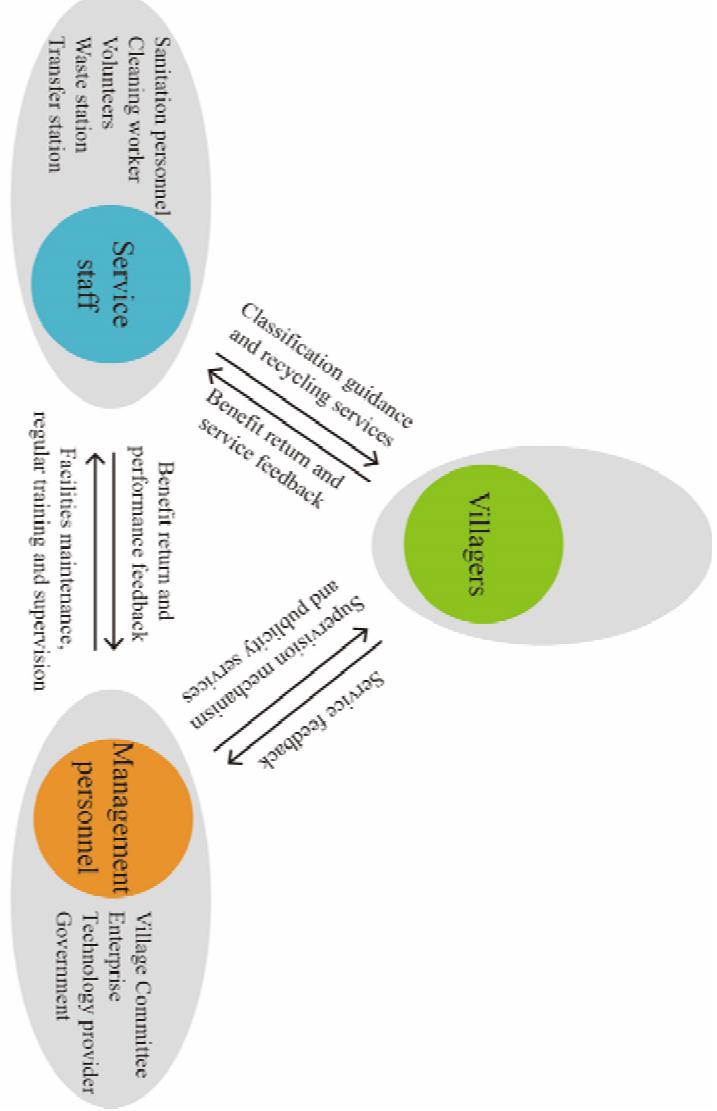

Figure 3: Stakeholders Map in Rural Waste Classification System

(1) Analysis of the need of service recipients

This study took Nanjing as the subject and investigated villagers randomly chosen from three villages via interview and questionnaire. A total of 96 questionnaires were distributed, with 84 of them being valid. The study surveyed the gender, age, awareness and attitudes of daily garbage classification among rural residents.

According to the results, the rural residents tend to lack 
environmental awareness, with stringent ideas and a lack of awareness of the classification of domestic waste. Most garbage goes to the wrong bin. Problems like the absence of a uniform labeling system, the lack of appropriate classification of waste bin as well as inconvenience of utilization have prevented users from correctly classifying garbage.

(2) Analysis of the needs of service providers

In the rural waste classification system, sanitation staff and village committee members are the key service personnel that affect users' perception of the service. This paper studied the specific needs of sanitation staff and village committee managers by following and interviewing villagers, and found:

The cleaning staff are older, who have to work in a harsh environment for garbage removal and collection. Works like carrying garbage bins and dumping garbage are mainly completed by manpower. Workers are exhausted by the long transportation route and frequent bending. The demand for classified collection and the contact with garbage and dirt would lower the efficiency of workers.

The village committee members are mainly responsible for the supervision of garbage classification in the village. However, there is a great consumption of manpower and resources as the government has to dispatch people to supervise the weight of existing garbage and store the data for a long time. Meanwhile, the mixed stacking of garbage for a long time, mosquito breeding and air pollution are not conducive to creating a clean and sanitary rural environment nor creating a good community.

\subsection{Investigation and analysis of procedures involved in existing service encounter}

The service encounter procedures of rural waste classification system mainly include stages like garbage dumping, recycling and supervision (Figure 4). In the stage of classified garbage dumping, villagers need to classify garbage and place them in different bags before dumping them in the waste bin near their house. The multiple processes would increase the contact between villagers and the waste, causing negative feelings such as dislike and boredom; The classification and recovery stage can be roughly divided into several steps, such as waste bin loading, driving and transportation, garbage dumping and collection, garbage bin unloading, etc. The cleaning staff need to bend over several times to finish procedures including dumping the garbage into the waste bin into the vehicle-mounted garbage bin, resulting in a long contact between the cleaning staff and the garbage bin and garbage. The huge workload would hamper the workers' classification and recovery efficiency; In the stage of classification supervision, the village committee members observe the garbage bins at the entrance of the village households and supervise the garbage classification of each villager, which requires a lot of manpower to record and count the data.

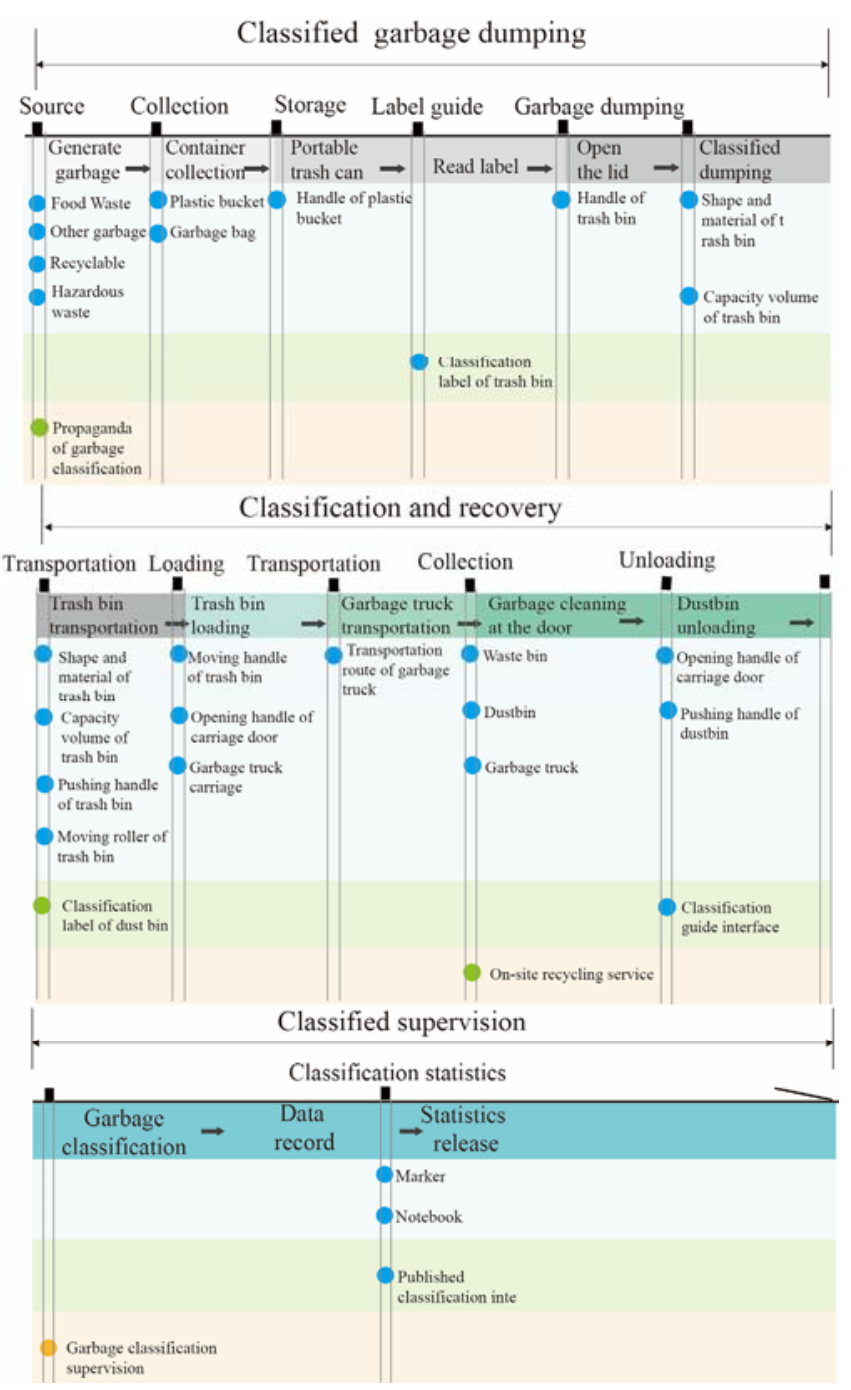

Figure 4 Existing Service Encounter Procedures of New Rural Waste Classification System

\subsection{Detailed analysis of existing service encounter points}

(1) Investigation and analysis of physical encounter points Physical encounter points in the waste classification system include products and facilities such as trash cans at the door, public trash cans and double-barrel lightering trucks, which run through the whole classification and recycling process, affecting the villagers' classification and recycling experience and the recycling efficiency of sanitation staff.

In the stage of garbage classification and dumping, as the garbage can lacks sealing and classification functions and most barrels are designed without covers, they can hardly support garbage classification since they are scattered in indoor kitchens, living rooms and courtyards in the form of single barrel. Therefore, it is difficult to ensure temporary storage of classified garbage by villagers. At the same time, the trash can is usually placed in a low position, requiring the villagers to touch the handle to open the lid, which could be polluted by dirt and bacteria, and it is easy to have the idea of unwilling to touch. As villagers don't want to touch the handle and dump garbage in, the garbage tends to spill over the 
ground and pollute the environment (Figure 5).
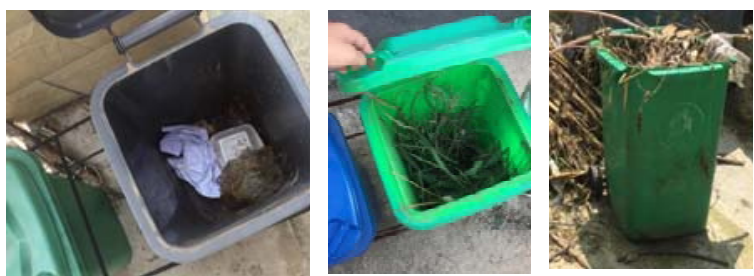

Figure 5 Incorrect Classification, Inconvenience in Opening Trash Bin and Garbage Spilling

In the stage of classification and recovery, the sanitation staff need to transport the garbage bins from the centralized point to the double-bucket lightering garbage truck (Figure 6), and transport them to the door of each villager, dump the garbage in the garbage bins at the door into the vehicle-mounted garbage bins, transport them to the centralized dumping point, unload the garbage bins, and wait for unified removal. As the garbage bin is heavy and not easy to move, when the box is transported and loaded, the dumping of garbage in the bucket needs the workers to get off the bus several times during collection. Also, the untimely cleaning of garbage in the bucket needs workers to repeat the cleaning and recycling process, thus increasing their workload.
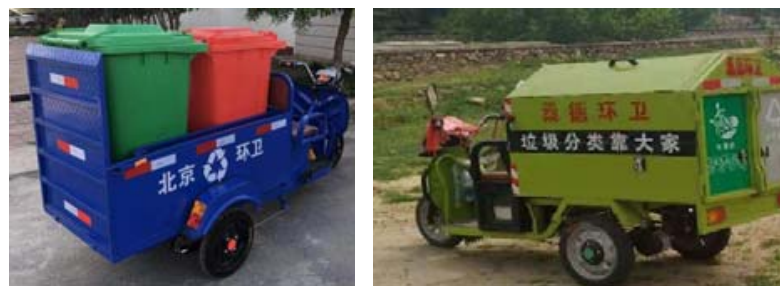

Figure 6 Transport Vehicle of Waste Classification and Collection in Rural Areas

(2) Investigation and analysis of information encounter points

The common information encounter points in the waste classification system include classified labels, public classified interface, classified dumping guide. Visual elements such as graphics, colors and words to transmit information on garbage classification ${ }^{[9]}$ is the key to guide and instruct users to dump garbage correctly in the waste classification system.

In the stage of garbage dumping and classification, the classification labels fail to fully explain to the public how to classify garbage because it is not highly recognizable, preventing the classification information to be effectively conveyed to the public and causing confusions among villagers in garbage classification. First of all, the color of waste classification marks is confusing, as shown in Figure7-1. Green trash cans represent both recyclable waste and food waste, which can easily cause confusion and affect the accuracy of waste classification. Secondly, there is inconsistency between the logo and the facilities in terms of color, as shown in Figure 7-2. The contrast color between the logo and the box is weak, and the white graphic background reduces the visibility of the logo, the background color of which is almost mixed with that of the trash can. Finally, the classification labels of garbage are not perfect, as shown in Figure 7-3. Although the four categories of recyclable materials, food waste, other materials and harmful materials have been designated, the auxiliary labels of each category cannot cover the scope of garbage classification and collection, and it is difficult for villagers to accurately classify and dump garbage through the guidance of labels.

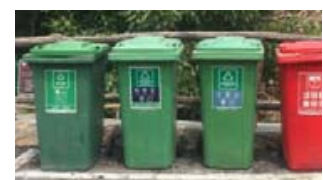

7-1

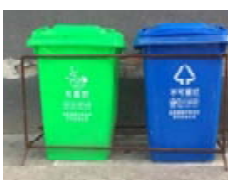

7-2

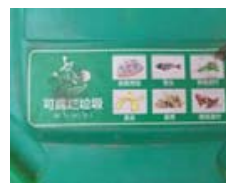

$7-3$
Figure 7 Present Trash Can Classification and Labels

In the stage of classification supervision, villagers obtain daily garbage classification data through the classification bulletin board, and the classification information is displayed in traditional forms of text and table (Figure 10). For villagers, traditional information delivery methods such as graphics, characters and colors prove inefficient in conveying information in a timely and intuitive manner, and there is a lack of interaction between the delivery of classification data and villagers.
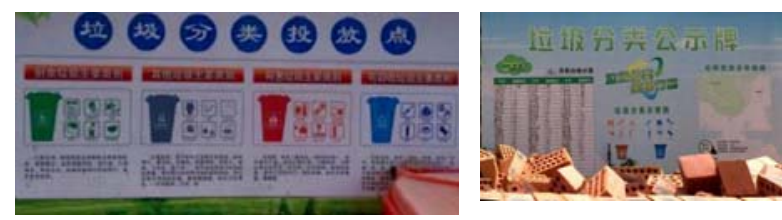

Figure 8 Classified Garbage Dumping Guide and Public Classification Bulletin Board

(3) Survey and analysis of interpersonal encounter points

Interpersonal encounter point refers to the interactive contact between villagers and sanitation staff when garbage is classified and recycled. The repeated dumping and beating of the trash can at the door is noisy, causing negative feelings among villagers and pressuring the sanitation staff. Therefore, the tedious task could arouse conflicts between the sanitation staff and the villagers.

\section{Strategies to Optimize Service Encounter of New Rural Waste Classification System}

\subsection{Establish a convenient encounter process for garbage classification services}

The simplification of garbage classification aims to offer easy and accessible garbage classification services to users so as to enhance user experience. With intelligent automatic recycling facilities and information terminals as carriers, an encounter process is established which features guidance-oriented services conforming to public perception before garbage dumping, accurate classification and recycling during garbage dumping, and accurate household incentive services after garbage 
dumping (Figure 9). It optimizes villagers' classification experience and enhances villagers' participation and enthusiasm in garbage classification behavior. The process goes as follows.

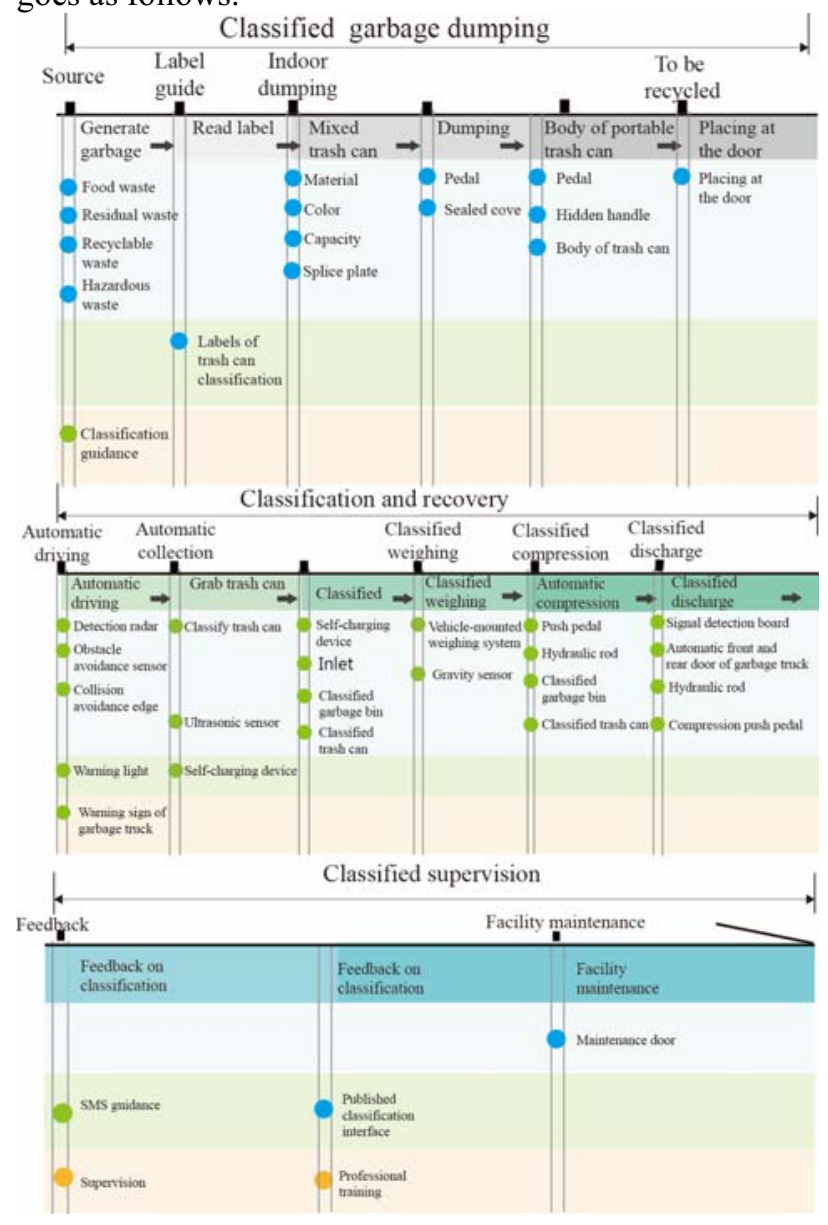

Figure 9 Optimizing Encounter Procedures of New Rural Waste Classification Services

Interpersonal encounter point refers to the interactive contact between villagers and sanitation staff when garbage is classified and recycled, as shown in Figure 11. The repeated dumping and beating of the trash can at the door is noisy, causing negative feelings among villagers and pressuring the sanitation staff. Therefore, the tedious task could arouse conflicts between the sanitation staff and the villagers.

In the stage of classified garbage dumping, standardized household garbage bins and garbage bags are distributed to villagers, who are expected to store them in classified garbage bins based on the four categories: food waste, others, recyclable materials and harmful materials. The spilling garbage needs to be placed in the barrels at the door for garbage trucks to collect them, which is convenient for delivery;

In the stage of classification and recycling, procedures such as loading and unloading garbage bins, classifying, collecting and removing garbage are accomplished by automatic driving technology to enable automatic transportation, automatic classification and collection, and automatic classification and unloading of garbage classification vehicles, thus reducing the pressure of sanitation staff and ensuring the efficiency of the transportation of classified and recycled garbage;

In the stage of classification supervision, garbage trucks, garbage bins and other intelligent terminals would use technologies based on Internet of Things such as sensors and two-dimensional codes to analyze and manage villagers' garbage classification data, establish garbage classification files for villagers, send the classification data to the intelligent classification bulletin board via the background control system, and offer feedback on the classification data in time to form a complete system integrating feedback, recording and management of classification information.

\subsection{Offer guided services in line with villagers' cognitive behavior}

The existing rural waste classification and recycling system is based on the garbage classification technologies introduced in the industrial era ${ }^{[10]}$, which weakens the effect of source garbage classification and ignores user experience. Therefore, it is necessary to optimize the classification and guidance on the villagers' stance.

(1) Before the classification is put into use, guidance combining visual contact and interpersonal contact can be adopted to improve villagers' awareness of classification. Among them, the visual contact should use intuitive elements such as characters, figures and colors to illustrate the rules of the rural waste classification system(Figure 10). This would enable villagers to classify and dump garbage by identifying labels, graphics and color in an easy way ${ }^{[11]}$. Establish standard visuals and colors for trash can logo at the visual encounter points, and guide users to identify these signs before dumping garbage while offering personalized classification and guidance services. For example, Houyi Village in Nanjing regularly dispatches personnel to guide villagers who have difficulties in garbage classification. They also invite rural residents and children to participate in the classification contest, hold public meetings on classification for the elderly, publicize the significance of garbage classification, thus encouraging everyone to participate in the process.

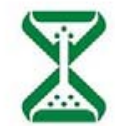

厨余垃圾
Food Waste
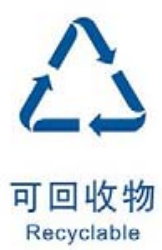

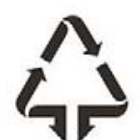

其他垃圾 Residual Waste

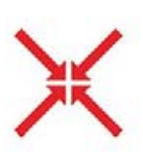

有害垃圾
Figure 10 National Standard of Waste Classification in 2019

(2) After the classification is put into use, an encounter point of classification guidance is established. When the service personnel screen garbage for secondary classification, they will text villagers who fail to classify garbage correctly. The bulletin board will announce the classification result of villagers, and service personnel will be sent to guide villagers below the participation and qualification standard. 


\subsection{Optimize collaborative services aiming at accurate garbage dumping}

Another reason why villagers don't want to classify garbage is that they don't know how to classify it correctly. Factors like the lack of classification function and spilling of garbage bins, delayed response from the waste recycling station, and non-transparent prices of waste prices have affected the accuracy of garbage classification and dumping and lower their enthusiasm of participation. Only when the service recipients and service providers in the service system respect, understand each other and work together would we guarantee service quality [12]. Therefore, to make sure villagers dump garbage into the right garbage bin, it is necessary to adopt new policies such as publicity and supervision by the village committee, participation of sanitation staff in garbage transportation, garbage recycling by professional companies, and active involvement of villagers, creating a process called "multistakeholder cooperation" (Figure 11). In this way, we could improve the overall accuracy of each link of the waste classification system, which goes as follows.

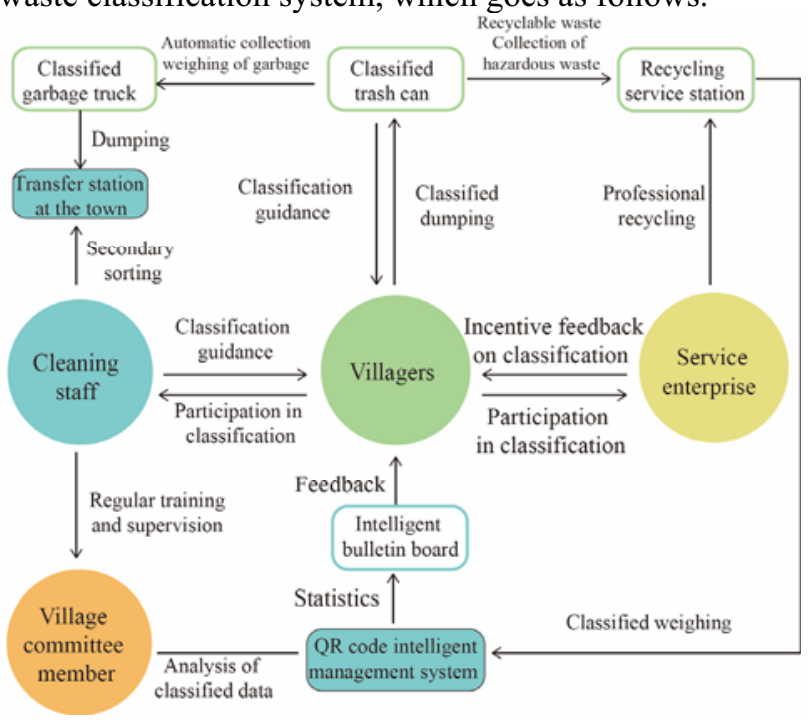

Figure 11 Multi Stakeholder Cooperation

(1) The village committee is responsible for propaganda while committee members take charge of the placement of trash bins that are free and easy to use so as to encourage more people to participate in this process.

(2) Service personnel need to work efficiently in clearing and transporting, reduce the workload of sanitation staff, upgrade the recycling facilities of classified garbage trucks, equip the trucks with infrared detection systems and lidar systems, shorten transportation route and reduce garbage transfer boxes, supplement facilities like classified carriages, automatic loading and unloading devices, sensor door of the carriage and other encounter points, add functions such as automatic movement, automatic collection, classified storage, automatic compression, automatic unloading, enabling automatic collection, compression and transportation of food waste and other garbage as well as automatic unloading of food waste and other garbage at the transfer station, thus improving classification services.

(3) Professional companies need to set up recycling service stations. For example, the "Haolei" Service Station in Liyu Village, Shandong Province (Figure 12) classified recyclable garbage classify into three categories: paper, metal and fabrics. Villagers are responsible for the initial classification of garbage and deliver them to the service points. Villagers can $\log$ into their account to classify and weigh the garbage in the intelligent garbage bins and profit from it. Finally, professional recycling companies will recycle the materials. In this way, the garbage is classified in a detailed manner, which is beneficial to both villagers and companies.
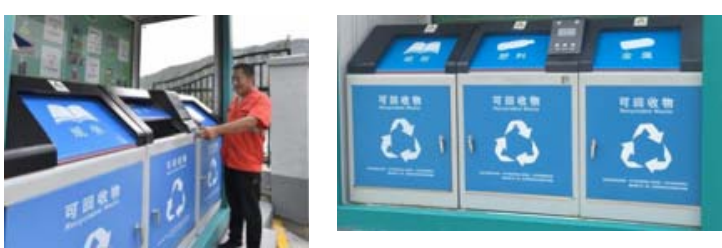

Figure 12 "Haolei" Service Station in Liyu Village, Shandong

\subsection{Establish door-to-door waste classification incentive service}

For users, classification guidance and improved classification recycling services are not enough for them to keep the habit of garbage classification for a long time. In order to encourage villagers to keep this habit and supervise their classification behavior, we can offer incentives to users to increase users' stickiness and improve the waste classification services in rural areas.

For rural areas, we can create an intelligent waste classification system by collecting villagers' information and issuing QR codes for village households based on the Internet of Things like sensor and other technologies. First, villagers stick QR code to the classified garbage bags and store them in garbage bins at door. Secondly, the ultrasonic sensors inside the intelligent garbage truck reads the information of the village households, analyzes and saves the weight of classified garbage by the vehicle-mounted weighing sensor and cloud computing technology, and converts the value of the garbage into bonus points, which are saved in the family account. Finally, the recycling service station intelligently identifies the user information, and the villagers can check the bonus points in their account through the intelligent classification bulletin board. Correct classification and dumping will be rewarded with bonus points, which can be used to redeem prizes, thus encouraging participation at the household level.

The incentive services at the household level can greatly improve the accuracy of garbage classification, conducive to the cultivation of villagers' awareness and encouraging participation. In addition, the village Committee members can also analyze the accuracy of classification based on big data, such as classification frequency and garbage weight to provide standardized and accurate garbage classification supervision services for villagers. 


\section{Conclusion}

Rural environment is closely related to villagers' overall quality and awareness of environmental protection. Therefore, we cannot afford to stop advocating for environmental protection. Garbage classification and recycling is not only related to the overall quality and awareness of villagers at the front end of classification, but also relies on service management and service quality ${ }^{[13]}$. In this paper, the concept of service design and service encounter is applied to the rural waste classification system, aiming at mining the needs of villagers, service personnel and management staff, reorganizing the existing procedures of service, proposing design of rural waste classification service encounter based on the needs of stakeholders and the current situation of service encounter. The efforts will guide the design of various encounter points so as to improve the service encounter process and system, enhance the overall experience of users, optimize the management and service quality of rural waste classification and create a healthy and harmonious social ecological environment.

\section{ACKNOWLEDGEMENT}

Jiangsu University Scientific Research Project(19C604)

\section{REFERENCES}

1. Yu Hansheng, Chen Yao. Research on Design and Application of Intelligent Waste Classification and Recycling System [J]. Packaging Engineering, 2018, 39(18):166-171.

2. Chashan. Micro Diary of Service Design 2 [Monograph] [M]. Beijing: Electronic Industry Press, 2017.

3. Deng Chenglian. Press the Button of Service Encounter Point [J]. Decoration, 2010, 000(006): P.13-17.

4. Lu Danqiong. Research on University Library Service Encounter Point Based on User Behavior [D]. Xi 'an: Shaanxi University of Science and Technology, 2018.

5. Zhu Mengran, Yan Xianglin, Yuan Qinqin. Service Encounter Theory and Its Application and Prospect in Information System Research [J]. Modern Intelligence, 2019(12).

6. James A Fitzsimmons. Service Management--Operation, Strategy and Information Technology [M]. Beijing: Mechanical Industry Press, 2000.

7. Shostack G L . Designing Services that Deliver[J]. Harvard Business Review, 1984, 62(1):133- 139.

8. Cao Jianqian, Yang Bing, Lan Xuanmei, et al. Mechanism of Benefiting from Waste Classification and Recycling under the Background of Ecological Governance-Based on Stakeholder Theory [J]. Value Engineering, 2019, 038(005):20-23.

9. Zhang Xiangquan. Research on Design of Information Interaction of Community Waste Classification System [J]. Journal of Hangzhou Dianzi University: Social Science Edition, 2017, 013(002):54-58.
10. Liu Jun. Research on the Design of Waste Classification and Recycling Service in Community Internet Plus - - Taking Wuhan Constellation Community as An Example [J]. Decoration, 2020(03):140-141.

11. Wu Wenyong. Research on Visual Design of Urban Public Trash Bin under the Background of Garbage Classification. Packaging Engineering.

12. Chashan. Micro Diary of Service Design 2 [Monograph] [M]. Beijing: Electronic Industry Press, 2015.

13. Ni Mengting, Qu Min, Xiong Xingfu. Analysis on the Classification of Garbage Bins in Scenic Spots Based on Service Design [J]. Packaging Engineering, 2019(22):214-218. 